\title{
Data-Driven Competitive Advantages in Digital Markets: An Overview of Data Value and Facilitating Factors
}

\author{
Victoria Fast ${ }^{(\varpi)}$, Daniel Schnurr, and Michael Wohlfarth \\ School of Business, Economics and Information Systems, University of Passau, Passau, \\ Germany \\ \{victoria.fast, daniel.schnurr, michael.wohlfarth\}@uni-passau.de
}

\begin{abstract}
Recent high-profile merger and antitrust cases as well as policy debates worldwide have focused on the relationship between access to (big) data and firms' competitive advantages in digital markets. These discussions have brought forward numerous conceptual arguments for and against the conjecture that market power may be derived from a firm's access to big data. Based on a review of the economic, information systems and management literature, this paper presents an overview of the aggregate empirical evidence on the business value and economic benefits that firms can indeed create from big data in the Internet economy. Moreover, six facilitating factors for data-driven market power are proposed that enable a firm to establish a sustained competitive advantage based on the economic benefits from data. Finally, we point to policy measures which may address competitive concerns in data-driven digital markets and highlight opportunities for future information systems policy research.
\end{abstract}

Keywords: Big data $\cdot$ Data-driven business models $\cdot$ Competition in digital markets $\cdot$ Market power $\cdot$ Regulation $\cdot$ Policy $\cdot$ Online platforms $\cdot$ Internet economy

Acknowledgments. This project was funded by the Bavarian State Ministry of Science and the Arts and coordinated by the Bavarian Research Institute for Digital Transformation (bidt). 